FUNCTIONAL AESTHETIC DENTISTRY - HOW TO ACHIEVE PREDICTABLE AESTHETIC RESULTS USING PRINCIPLES OF A 14 STABLE OCCLUSION

Neeraj Khanna

2020; Springer; 252 pp; ebook

ISBN: 9783030391140

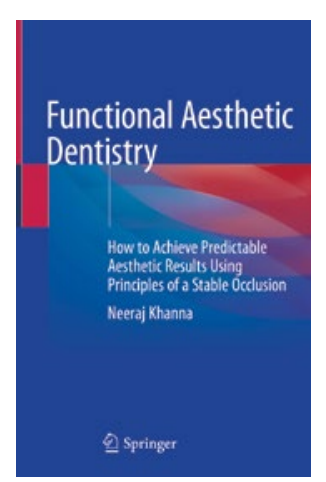

'This book is not meant to be a book of before and after photos, but one that explains the principles of occlusion and how this philosophy can be applied to patients from all walks of life. This philosophy does not discriminate, nor does it assume anything.'

Dr Khanna experienced an epiphany whilst attending a class given by $\mathrm{Dr}$ Peter Dawson which led him firstly to strive to become what Dawson called a 'physician of the masticatory system' and secondly to wish to 'help as many dentists as possible to understand this process of complete dentistry.' This book is the result.

Each chapter begins with a quotation which has meaning to the author and his life although not directly relevant to the text of the chapters themselves. The book consists of ten chapters covering: functional aesthetics; functional occlusion: understanding and thinking; the envelope of function: understanding and importance; the complete examination: the 12 steps needed to perform a complete exam; diagnostic records: what to take and why; incisal edge position: its importance to aesthetics and function; phonetics: how to design with phonetics in mind; diagnosis and treatment planning; communication with your patients/specialists/technicians; preparation, planning and quality control. Sadly, it does not contain an index but it is written in a very easy to read style. https://tinyurl.com/ ebooks-occlusion

\section{Janet Goodwin to be honoured with new FGDP award}

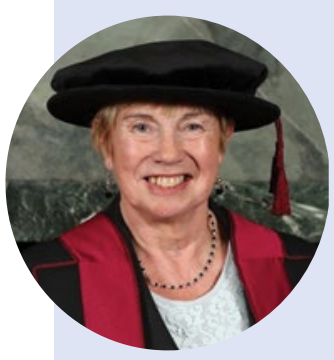

The Faculty of General Dental Practice (UK) (FGDP $[\mathrm{UK}]$ ) is honouring the legacy of the late Janet Goodwin FFGDP(UK)(Hon.) with an award to recognise the achievements of dental care professionals (DCPs).

Over a career spanning almost 50 years, Janet was a staunch advocate for the advancement and recognition of DCPs.

An Affiliate Member of FGDP, she served the Faculty as a representative for the interests of the wider dental team, chairing its DCP Committee, contributing to the development of standards and sitting on the National Faculty Board, and in 2019 she was awarded Honorary Fellowship.

The new Janet Goodwin Award will recognise leadership, standards of professionalism and patient care, commitment to life-long learning, service to the profession and advocacy for the whole-team approach to general dental care.

Open to all GDC-registered DCPs, the inaugural award will be made as part of the FGDP(UK) Annual Awards 2021, and the winner will also receive Affiliate Membership of the Faculty, and its associated benefits, for 2021-22. Nominations are open until 23:59 on Monday 1 March 2021.

Commenting on the new award, FGDP(UK) Dean Ian Mills said: 'Janet was a ground-breaking and influential figure in dentistry, and her passing was mourned throughout the dental profession. She was a fantastic ambassador for our profession, a passionate advocate for the role of the dental team, and a strong supporter of the Faculty. I am therefore delighted that we have been able to commemorate her contribution to dentistry by introducing an annual FGDP(UK) Annual Award in her memory'.

Further details are available at https://www.fgdp.org.uk/news/ fgdpuk-annual-awards-2021.

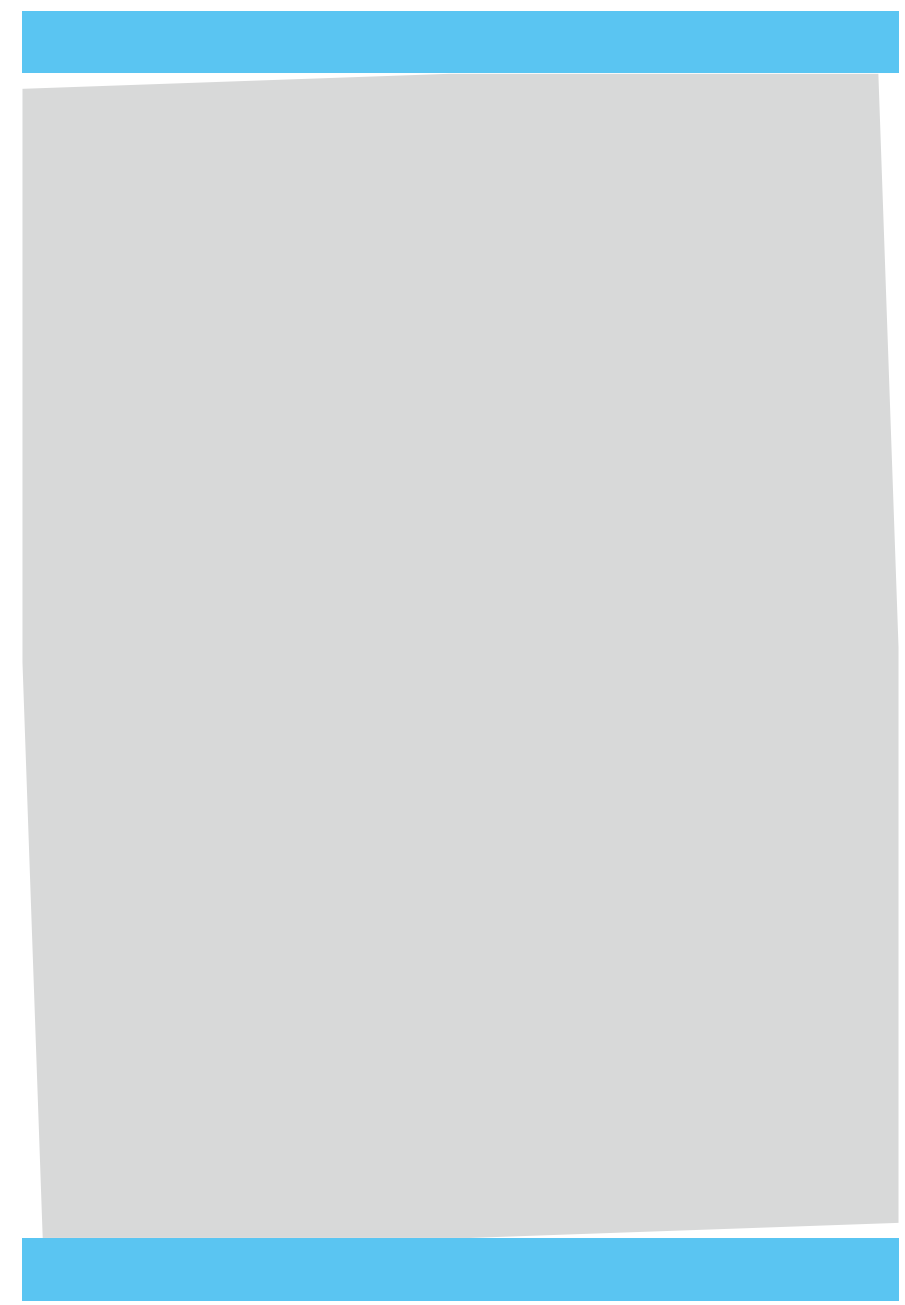

